\title{
Development and Performance Evaluation of Power Driven Chopper
}

\author{
Abayineh Awgichew \\ Post-harvest and Agricultural Product Processing Engineering Team Leader at Asella Agricultural Engineering Research Center, \\ Oromia Agricultural Research Institute, P.O. Box 06 Asella, Ethiopia. Email: abaw2001@gmail.com
}

Crossref

DOI: http://doi.org/10.38177/ajast.2020.4402

Copyright: @2020 Abayineh Awgichew. This is an open access article distributed under the terms of the Creative Commons Attribution License, which permits unrestricted use, distribution, and reproduction in any medium, provided the original author and source are credited.

\section{ABSTRACT}

Maize and sorghum stalk considered among the most fodder materials in Ethiopia. Therefore the chop machine was adapted and evaluated. The research was conducted at Asella Agricultural Engineering Research Center (AAERC), Arsi Negelle and Zuway Dugda districts to evaluate the machine performance in terms of chopping efficiency, throughput capacity, cutting efficiency and fuel consumption at different speed of cutter shaft. The output of chopper was found to be remarkable achievement. The chopping efficiency was decreased from 97.28 to $92.43 \%$ on maize stalk and 95 to $90.2 \%$ on sorghum stalk as rpm increases from 1150 to 1850 respectively. Throughput capacity of chopper was increases from 8.13 to 12.6 $\mathrm{kg} / \mathrm{min}$ on maize stalk and 10.26 to $14.5 \mathrm{~kg} / \mathrm{min}$ on sorghum stalk as rpm increases from 1150 to 1850 respectively. The mean of chopping length and cutting efficiency of $3.5 \mathrm{~cm}$ and $96.64 \%$ on maize and also $2.53 \mathrm{~cm}$ and $97.63 \%$ on sorghum stalk respectively.

Keywords: Throughput capacity, Cutting and chopping efficiency, Chop length.

\section{Background and Justification}

Livestock feed preparation is a great problem nowadays. Earlier time there is grazing area. But now the quest to increase the agricultural production in all facets, have intensified crop production by way of increasing cultivated areas thereby reducing the grazing areas. Livestock farmers especially in the sector of goats, sheep and cattle are constantly faced with problem of feed shortage during the dry season. The herd constantly relies on crop residue, but these are usually in short time.

The unavailability of sufficient feed during the dry season in the Ethiopia is a major problem in livestock production. During this period, grazing livestock lose weight and in extreme cases some deaths do occur.

Livestock production, productivity and its sustained development depend on the advancement of science and technology that will enhance production, processing, handling, storing of livestock feed. Chopping of animal feed is considered as a labour intensive processing operation in animal production system. Traditionally, animal feed, especially crop residue are chopped manually by a sickle in the farms of Ethiopia. It is a labor intensive, less efficient and time consuming operation.

Traditional technology for chopping of animal feed is even more inefficient and slow as well as old in case of medium and large farms. In the other hand in Arsi zone of sorghum and maize farmer have collect the head of the crop first and release their cattle, sheep and goat on it. These animals feed the leaf only and other stalk of remain on farm and finally they burn it. Some farmers also collect the stalk together for the dry period. But due to lack of chopper and other processing machine the loss is high. AGP 2 Technology constraint survey group, ADPLAC and Sinana Agricultural Research Center (SARC) also mention the scarcity and lack of such a technology for the processing of crop residue and the need to solve the utmost problem in livestock production appear to have 
Asian Journal of Applied Science and Technology

Volume 4, Issue 4, Pages 13-20, October-December 2020

compelled problem to request the development of an equitable technology. So, to alleviate problems stated above it was felt appropriate to develop engine driven chopper machine that can chop animal feed.

\section{Material and Method}

\subsection{Methods}

The manufacturing of the machine was based on the following criteria: (a) Availability of the materials, (b) Simplicity and ease of machine operation and repairs, (c) Adaptability of the machine. So based on gathered information from books and on the internet having the same concept as of animal feed chopping machine and on the basis of the related data the chopper was fabricated at AAERC machine shop, 2018.

\subsection{Machine Description}

The overall length, width and height of the machine were 148,188 and140 $\mathrm{cm}$ respectively. The machine consisted of five (5) major components are as follows: (1) The feeding table (2) the cutting assembly, (3) The frame stand assembly, (4) The power transmission assembly, and (5) The material outlet. Figure 1 show the developed machine used in the experiment.

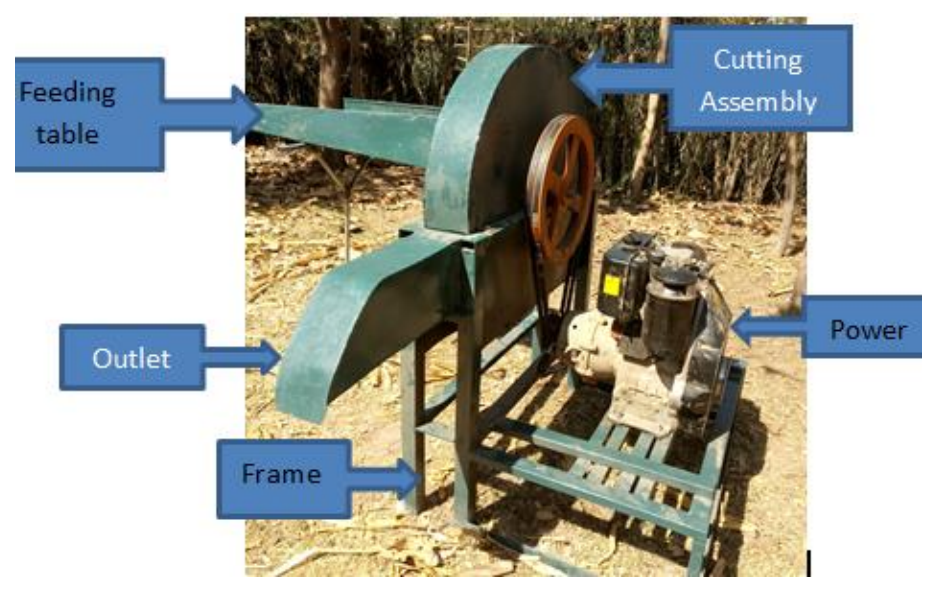

Figure 1: Chopper machine and Main Parts

\section{The Feeding table}

Part of the machine where in chopping material is put and prepared prior to feeding into the machine. It made up of $105 \mathrm{~cm} * 70 \mathrm{~cm}$ sheet metal with $1.5 \mathrm{~mm}$ thickness.

The Cutting unit: systems intend to cut the chopping material into short lengths with reasonable consistency within a range of optional settings. This unit consists of following parts: 1 . Cutter shaft: It is $30 \mathrm{~mm}$ diameter and $31.5 \mathrm{~cm}$ length in size supported by two P206 bearings. This shaft carries $35 \mathrm{~cm}$ diameter disc and $6 \mathrm{~mm}$ thickness. This disc was used to hold cutting blade fixed with bolt and nut. 2. Cutting blade: The thickness of cutter was $4 \mathrm{~mm}$ with length of $40 \mathrm{~cm}$ and $7.5 \mathrm{~cm}$ width. 3 . Cutting unit cover: It is half circle made up of $1 \mathrm{~mm}$ thickness sheet metal.

\section{Base and Stand Assembly}

Base and stand assembly is considered as the backbone of the machine functioned to support mainly all the parts of the machine. This is made up of steel bars and heavy duty mild steel to assure the durability of the materials. 


\section{Power Transmission Assembly}

Power transmission assembly is done by mechanical operation. This is made up of diesel engine, belt and pulley. The pulley diameter was $46 \mathrm{~cm}$ with double lines.

The outlet: An opening that permits exit/release of materials after chopping, made of $1.5 \mathrm{~mm}$ thickness sheet metal.

\section{Working principles}

The chopper is driven by a 10 horse power diesel engine which rotates the cutting blades via a coupling joint (pulley and belt). The chopping material is introduced into the machine manually over a feeding table by the operator with a slight push of the material into the cutting unit. After chopping, the material is then blown out of the cutting unit by the help of the centrifugal force of the cutting blades through the outlet. The trajectory of the chopped materials is controlled using an adjustable flap on the discharge chute.

\section{Experimental Site Description}

The experiment was conducted at Asella Agricultural Engineering Research Center (AAERC) located at $6^{\circ}$ 59' to $8^{\circ} 49^{\prime} \mathrm{N}$ latitudes and $38^{\circ} 41^{\prime}$ to $40^{\circ} 44^{\prime} \mathrm{E}$ longitudes, having an elevation of 2430 meters above sea level (masl), at Arsi Negelle, which is located at longitude and latitude of $7^{\circ} 21^{\prime} \mathrm{N} 38^{\circ} 42^{\prime} \mathrm{E}$ with an elevation of 2043 meters above sea level and Zuway Dugda which is located at latitude and longitude of $8^{\circ} \mathrm{N} 39^{\circ} \mathrm{E}$ with an elevation of $1687 \mathrm{~m}$.

\section{Preparation of Samples}

Samples for experimental investigations were prepared from materials obtained after harvesting of maize and sorghum stalk. Five kilogram of samples with three replications were taken, chopped and weighed to determine the mass of chopped materials after commencing on the experiment.

\section{Performance evaluation}

The performance of the chopper was evaluated using maize and sorghum stalk. The moisture content of the chopping materials was determined using a forced air oven. For each testing run, $5 \mathrm{~kg}$ of chopping material was weighed using a digital weighing scale and the length of materials was measured using measuring tape. The materials were then fed into the cutting chamber of the chopper via the feeding table. The chopped materials were then collected in a sack to determine the length of the chop and weight. The time taken to chop quantity of chopping materials was recorded using a stop watch. A total of three test runs were made in order to obtain an average measure of the performance parameters. Then to assess the efficiency of the chopper prototype in performing the intended purpose, the following criteria was adopted.

Cutting efficiency: Cutting efficiency was calculated by measuring the stem length before cutting and the size or length of particles after cutting. (Elfatih et al., 2010). The length of materials was measured using measuring tape.

$$
C_{E}=\frac{\left(L_{b}-L_{a}\right)}{L_{b}} * 100 \%
$$

Where: $\mathrm{C}_{\mathrm{E}}=$ cutting efficiency $(\%), \mathrm{L}_{\mathrm{b}}=$ Particles length before cutting, $\mathrm{cm}, \mathrm{L}_{\mathrm{a}}=$ Residual length after cutting, $\mathrm{cm}$ 


\section{Chopping efficiency}

Chopping (machine) Efficiency is the ratio of the weight of the accepted output and input expressed in percent. Chopping efficiency of the machines was calculated as (Khope and Modak, 2013)

$$
C_{o}=\frac{W_{c}}{W_{f}} * 100
$$

Where, $\mathrm{Co}=$ Chopping efficiency, $\mathrm{Wf}=$ Total weight of samples fed in, $\mathrm{Wc}=$ Total weight of chopped out.

\section{Throughput capacity}

Throughput, defined herein as the amount of forage chopped per hour when the machine is operating at optimal capacity (Harry and John, 2007). This was assessed by chopping a known amount of forage in a given time period. The quantity of forages was measured by a digital weighing balance while the time taken was measured using a stop watch.

$$
C_{r}=\frac{W_{f}}{t_{c}} * 100
$$

Where, $\mathrm{tc}=$ Chopping time in seconds.

\section{Estimation of Fuel consumption}

To measure the fuel consumption, first chopper machine kept on leveled surface. The fuel tank was filled up to top of the tank before the test started. After the completion of the chopping operation the engine was stopped and then the tank refilled to the original level.

The quantity of fuel filled in the tank was measured using graduated measuring cylinder. The difference between amount of fuel prior to and after chopping was used to estimate fuel use efficiency.

\section{Statistical Analysis}

Data were subjected to analysis of variance following a procedure appropriate to the design of the experiment as recommended by Gomez and Gomez (1984). Analysis was made using statistix 8.0 statistical software. The treatment means that were different at $5 \%$ and $1 \%$ levels of significance were separated using LSD. Level of significance $(\mathrm{P})$ for these relations was obtained by $\mathrm{F}$ - test based on analysis of variance.

\section{Result and Discussion}

Each sample was weighted (mass before chopped) and passed to inlet into the cutting unit, coming into contact with the cutter blade. The chopped materials were collected through the outlet. The time taken to chop each sample was recorded. The collected materials were weighted as mass after chopped.

Each test replicated three times. The specific chopping resistance increases with the increase of the stalks fed through the chute. The prototype was tested using maize and sorghum stalk and the results were presented in the table 1 . 
Asian Journal of Applied Science and Technology Volume 4, Issue 4, Pages 13-20, October-December 2020

Table1: Summarized Performance evaluation result of the prototype

\begin{tabular}{|c|c|c|c|c|c|c|c|c|c|c|}
\hline \multirow[t]{2}{*}{ Parameters } & \multicolumn{5}{|c|}{ Maize stalk } & \multicolumn{5}{|c|}{ Sorghum stalk } \\
\hline & 1150 & 1450 & 1850 & $\mathrm{CV}$ & SEM & 1150 & 1450 & 1850 & $\mathrm{CV}$ & SEM \\
\hline Cutting efficiency (\%) & 95.8 & 96.53 & 97.6 & 0.62 & 0.34 & 96.8 & 97.5 & 98.6 & 0.61 & 0.34 \\
\hline $\begin{array}{l}\text { Chopping efficiency } \\
(\%)\end{array}$ & 97.28 & 94.48 & 92.43 & 0.6 & 0.33 & 95 & 92.3 & 90.2 & 0.62 & 0.33 \\
\hline $\begin{array}{l}\text { Throughput capacity } \\
\text { (kg/min) }\end{array}$ & 8.13 & 10.73 & $12 . .6$ & 4.25 & 0.22 & $\begin{array}{c}10.2 \\
6\end{array}$ & 13 & 14.5 & 7.68 & 0.48 \\
\hline Chop length (m) & 0.039 & 0.036 & 0.032 & 4.15 & 1.2 & 0.30 & 0.025 & 0.021 & 4.47 & 9.71 \\
\hline $\begin{array}{l}\text { Fuel consumption } \\
\text { (lit/qnt) }\end{array}$ & \multicolumn{5}{|c|}{0.22} & \multicolumn{5}{|c|}{0.20} \\
\hline
\end{tabular}

\section{Chop length}

Mechanization of the forage chopping process is intended to reduce on farm labor demand and drudgery while improving feed intake and feed use efficiency. As shown in table 1 the mean chop length of both maize and sorghum stalk was decreased from 0.039 to $0.032 \mathrm{~m}$ and 0.03 to $0.021 \mathrm{~m}$ as RMP increased from 1150 to 1850 respectively. By adjusting the flap on outlet only it can be possible to get less chop length.

Forage particle length has a critical influence on feed intake and the functionality of the rumen in dairy cattle (Bhandari et al., 2007; Yang and Beauchemin, 2009). The mean chop length produced by the prototype was within the acceptable range of between 1 to $4 \mathrm{~cm}$ required to maintain proper rumination and salivation (Moharrery, 2010) as sited by Kiggundu M, 2018. When subjecting the data to Analysis of Variance there are no significant pairwise differences among the means chop length.

\section{Cutting efficiency}

Cutting efficiency was highly affected by RPM of the cutter blade shaft linearly. As can be seen in table 1 all mean of cutting efficiency of machine are significantly different from one another. Cutting efficiency was increased from 95.8 to $97.6 \%$ and 96.8 to $98.6 \%$ on maize and sorghum stalk respectively as RPM increased from 1150 to1850.

\section{Chopping efficiency}

Table 1 indicates that maize stalk has the higher Means of chopping efficiency which are 97.28, 94.48 and $92.43 \%$ at 1150, 1450 and 1850 RPM respectively. Whereas means of chopping efficiency of sorghum stalk were 95, 92.3 and $90.2 \%$ at 1150,1450 and $1850 \mathrm{rpm}$ respectively.

This means that the stalk type affects significantly to the study of throughput capacity. This due to sorghum stalk was chopped in short length than of maize stalk so it may has tendency to blown away. 


\section{Throughput Capacity of machine}

From the table 1, it was observed that when the machine was loaded by the test material, 1850 RMP of cutter shaft has highest the throughput capacity of $756 \mathrm{~kg} / \mathrm{hr}$ followed by $1450 \mathrm{PM}$ which is $643.8 \mathrm{~kg} / \mathrm{hr}$ and then $487.8 \mathrm{~kg} / \mathrm{hr}$ at 1150 RPM on maize stalk. Whereas on sorghum stalk throughput capacity were $615.6,780$ and $870 \mathrm{~kg} / \mathrm{hr}$ at 1150 , 1450 and $1850 \mathrm{rpm}$ respectively. Subjecting the data to Analysis of Variance shows means of throughput capacity of machine on maize and sorghum stalk were highly significant at $1 \%$ level of significance. This means that the chopping machine can has a highest throughput capacity when RPM of cutting blade shaft is 1850 was used because of its fast rpm. Thus chopping time was faster. This result has similar trend with Saanoding et al., 2016.

\section{Percent loss}

Figure 2 shows the Percent Loss of the Chopper Machine when fed by $5 \mathrm{~kg}$ of maize and sorghum stalk with three (3) different rpm with three replications. The graph reveals that the $1850 \mathrm{rpm}$ has the highest mean of Percent Loss which is $(7.57 \%)$, followed by $1450 \mathrm{rpm}(5.52 \%)$, and $1150 \mathrm{rpm}(2.72 \%)$ respectively on maize stalk and 4.97, 7.74 and $9.82 \%$ at 1150,1450 and 1850 rpm respectively.

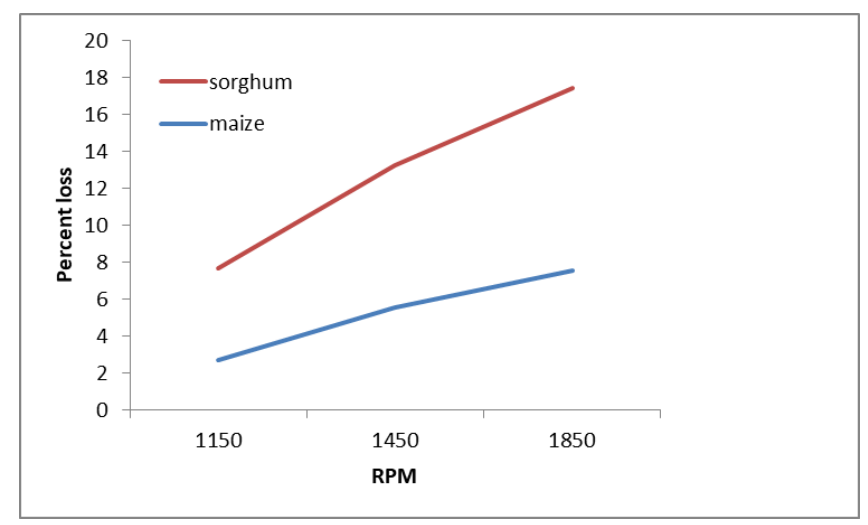

Figure 2: Effect of rpm on percent loss

Analysis of Variance, Table 2 shows significant treatment mean differences at 5\% level of significance, which means that the three different rpm of cutter blade affects significantly to the study of Percent Loss. The rpm 1850 has the highest Percentage Loss because it has the fastest among the three rpm. It means that the faster the revolution per minute (rpm) the highest the Percentage of loss. The result obtained was contradicted with Saanoding A, 2016

Table 2: ANOVA table of percent loss of machine

\begin{tabular}{|lcclll|}
\hline Source & DF & SS & MS & F & P \\
\hline REP & 2 & 0.8374 & 0.4187 & & \\
\hline RPM & 2 & 35.5190 & 17.7595 & $55.07^{*}$ & 0.0012 \\
& & & & & \\
\hline Error & 4 & 1.2900 & 0.3225 & & \\
& & & & & \\
\hline Total & 8 & 37.6465 & & & \\
\hline
\end{tabular}




\section{Fuel consumption}

Fuel consumption of chopper machine was a little varies from crop to crop residue but not significant. As shown from Table, the average fuel consumption of machine for chopping of one quintal of maize and sorghum stalk were 0.22 and 0.2 liter respectively.

\section{Estimation of Machine Cost}

The cost of the machine includes raw material cost and production (machine and labor) cost only. Materials wastage and overhead costs are estimated from raw material and production cost.

Table 3: The summarized cost of the machine without engine

\begin{tabular}{|l|l|c|}
\hline No & Parameters & Cost (ETB) \\
\hline $\mathbf{1}$ & Raw material & 4498.98 \\
\hline $\mathbf{2}$ & Materials wastage $=2.5 \% 1$ & 112.5 \\
\hline $\mathbf{3}$ & Production (machine + labor) & 1023.88 \\
\hline $\mathbf{4}$ & Overhead = 5 \% of 3 & 51.194 \\
\hline $\mathbf{5}$ & Profit = 10 \% of $(1+2+3+4)$ & 568.65 \\
\hline $\mathbf{6}$ & Sell tax = 15 \% of $(1+2+3+4+5)$ & 938.3 \\
\hline $\mathbf{7}$ & Selling price $=(1+2+3+4+5+6)$ & $\mathbf{7 1 9 3 . 5}$ \\
\hline
\end{tabular}

\section{Conclusion and summary}

\section{Conclusion}

Performance evaluations of the machines were done to determine chopping capacity, chopping efficiencies and associated losses at different speeds and constant feed rate. Three levels of cutter blade speed (1150, 1450 and 1850 rpm) were investigated to identify the optimum combination of the variables in question. The chopper was subjected to test using available material such as Maize stalk and sorghum stalk. The speed of the cutting blade affects the length of cut and throughput capacity.

\section{Summary}

The chopper prototype is a simple, low-cost and versatile prototype powered by a 10.0 horsepower diesel engine that can be used to chop a variety of chopping materials. Throughput capacity increased from 487.8 to $756 \mathrm{~kg} / \mathrm{hr}$ on maize stalk and 615.6 to $870 \mathrm{~kg} / \mathrm{hr}$ on sorghum stalk as speed increases from 1150 to $1850 \mathrm{rpm}$ respectively. Whereas chop length decrease from 3 to $2.1 \mathrm{~cm}$ on sorghum stalk and 3.9 to 3.2 with speed increasing from 1150 to 1850 pm respectively. Percent loss and throughput capacity have direct linear relation with speed whereas Chop length and chopping efficiency were vice versa. The machine was used 0.22 and 0.2 liter of diesel to chop $100 \mathrm{~kg}$ of maize and sorghum stalk respectively. 


\section{Recommendations}

Recommendations with respect to my parameter are as follows

$>$ For future commercialization the use of higher speed is recommended.

$>$ The efficiency of the machine does not only based on the machine's speed itself but also on the blade and shear bar clearance, so clearance and materials selection must be considered.

$>$ Since the engine sit was fixed and take wider area, made the machine large and the transportation difficult; hence a removable engine sit must be developed and used.

\section{References}

Bhandari, S.K., Ominski, K.H., Wittenberg, K.M. and Plaizier, J.C., 2007. Effects of Chop Length of Alfalfa and Corn Silage on Milk Production and Rumen Fermentation of Dairy Cows 2355-2366

Elfatih. A., E. M. Arif, and Atef, A. E, 2010. Evaluate the Modified Chopper for Rice Straw Composting. Journal of Applied Sciences Research, 6(8): 1125-1131

Gomez, A.K. and A. A. Gomez. 1984. Statistical Procedures for Agricultural Research. John Wiley \& Sons. New York, USA

Harry, L.F. and John, B.S., 2007. Introduction to Agricultural Engineering technology: A problem solving approach, Third (Springer Science+Business Media LLC)

Khope P.B. And, J.P.Modak, 2013. Development and Performance Evaluation of a Human Powered Flywheel Motor Operated Forge Cutter. International Journal of Scientific \& Technology Research Volume 2 (3).

Kiggundu M, Kato H, Komakech J and Mugerwa S, 2018. Design and performance evaluation of a NARO forage chopper prototype for smallholder dairying systems. International Research Journal of Engineering and Technology (IRJET).

Moharrery, A., 2010. Effect of Particle Size of Forage in the Dairy Ration on Feed Intake, Production Parameters and Quantification of Manure Index 23, 483-490

Yang, W.Z. and Beauchemin, K.A., 2009. Increasing physically effective fiber content of dairy cow diets Saanoding A. B, Rasid M. P, Alex L. S and Ysmail A. B. Design, Fabrication, and Evaluation of Forage Chopper Machine using three Different Diameter Pulleys. International Journal of Humanities and Social Sciences. Vol. 9, No. 2, pp. 100-11 